\title{
EL AGUA EN YECLA (MURCIA): PASADO Y FUTURO DE UN RECURSO IMPRESCINDIBLE PARA EL DESARROLLO LOCAL
}

\author{
Francisco José Morales Yago \\ Universidad Nacional de Educación a Distancia. \\ fjmorales@geo.uned.es
}

\section{RESUMEN}

El agua es un elemento imprescindible en el desarrollo de las sociedades actuales, es necesaria una mentalización ciudadana sobre el consumo racional de la misma así como mejoras en el saneamiento de la red de abastecimiento y mantenimiento de un óptimo nivel de calidad.

La eficaz gestión de las aguas residuales y aumento del reciclaje juegan un papel decisivo, también la posibilidad de recurrir a recursos hídricos externos es una propuesta necesaria para compatibilizar un crecimiento sostenible necesario que pueda dar respuesta a los retos planteados en el espacio geográfico estudiado, localizado en las tierras de SE español, concretamente en el municipio de Yecla, al norte de la Región de Murcia.

Palabras clave: agua, sostenibilidad, paisaje, agricultura, abastecimiento hídrico.

\section{ABSTRACT}

Water is an essential element in the development of modern societies, we need a citizen awareness on the rational use of the same as well as improvements in sanitation supply network and maintaining an optimal level of quality.

The effective wastewater management and recycling increased play a decisive role, the possibility of using external water resources is a necessary proposal to reconcile sustaina-

Fecha de recepción: abril 2013.

Fecha de aceptación: diciembre 2013. 
ble growth need to be able to respond to the challenges in geographic space studied, located SE in Spanish lands, specifically in the town of Yecla, north of the Region of Murcia.

Keywords: water, sustainability, landscape, agriculture, Yecla.

\section{INTRODUCCIÓN}

El agua está sobre nosotros, bajo nosotros, junto a nosotros; incluso podríamos afirmar que nosotros mismos somos agua ya que nuestro cuerpo está constituido al menos por un $65 \%$ de agua. La existencia de este elemento significa la presencia de vida y ello motiva la intervención de la acción humana que tiene capacidad para crear una nueva configuración y transformación del paisaje.

Las sociedades humanas desde la noche de los tiempos han recurrido al agua como garante de su bienestar y progreso e incluso le han rendido culto como un dios capaz de proporcionales lo necesario para el sustento en el día a día. Las finalidades del agua son cada vez más numerosas y al mismo tiempo la dependencia es absoluta, siendo conscientes de que se trata de un bien limitado, finito y cuya ausencia puede dar origen a múltiples conflictos así como a la desaparición de la vida.

El espacio objeto de nuestro trabajo se centra en Yecla (Murcia), el municipio más septentrional de la Comunidad Autónoma de la Región de Murcia, en el Sudeste español. A lo largo de su dilatada historia, estas tierras han recibido varias denominaciones, todos ellas bien encaminadas, destacando el rasgo predominante de su paisaje y la repercusión económica del mismo. Así por ejemplo, en la gran primera época de «unificación mediterránea» correspondiente al imperio Romano, estas tierras junto a otras circundantes, según el historiador Plinio, formaban parte del «Campus Espartarius», por tratarse de un amplio espacio cubierto de monte bajo cuya principal formación vegetal era el esparto. A finales del siglo XIX, aparece una nueva denominación «Tierras del Vino» (Morales A. 1972) puesto que el paisaje se transformó a través de la realización de muchas plantaciones de viñedo en la comarca tras el tratado de vinos con Francia, debido a la grave crisis de filoxera por la que atravesó el país vecino.

Continuando a través del tiempo a partir de la década de los años sesenta del siglo XX y todavía en la actualidad se mantienen dos nuevas nomenclaturas: «Tierras del mueble», totalmente justificado por el florecimiento industrial de la ciudad en esta época debido, a tareas dedicadas a la fabricación de mueble e industrias afines que tanta trascendencia han tenido en el desarrollo económico de la ciudad. La otra denominación se inscribe en el aspecto físico o geomorfológico del territorio: «El Altiplano» término paradójicamente más utilizado y el menos exacto de los recibidos puesto que se entiende como el «Altiplano de Murcia», a los términos municipales de Jumilla y Yecla.

Los factores naturales que dan carácter al territorio y que condicionan la expansión y forma de las localidades, generan expectativas capaces de impulsar o frenar las oportunidades de crecimiento económico y desarrollo social, precisamente el uso del agua es uno de los principales elementos que más trascendencia ha tenido en el pasado, presente y esencialmente futuro de este espacio geográfico, ya que de no asegurarse un abastecimiento suficiente se ponen en cuestión las expectativas de desarrollo y bienestar tan demandadas por nuestra sociedad actual 
Armonizar el consumo de agua y desarrollo socioeconómico de las sociedades actuales pasa por avanzar hacia un casi denostado «desarrollo sostenible», término aplicado al desarrollo económico y social que permite hacer frente a las necesidades del presente sin poner en peligro la capacidad de futuras generaciones para satisfacer sus necesidades en este caso hídricas. Ante esta sencilla definición de cara al futuro estimamos que las iniciativas referidas al uso de los escasos recursos hídricos existentes en el espacio objeto de estudio, deben contener diversas acciones que colaboren hacia el uso racional del agua y un máximo rendimiento contribuyendo de forma eficaz a la creación de riqueza y al sostenimiento actual del consumo humano y de las diversas actividades económicas implantadas en la ciudad tales como el sector industrial y las tareas agrícolas y de ocio cada vez más eficientes y con una proyección futura indiscutible en un contexto globalizado, competitivo donde el empuje de lo global no puede anular el desarrollo endógeno y la potencialidad local.

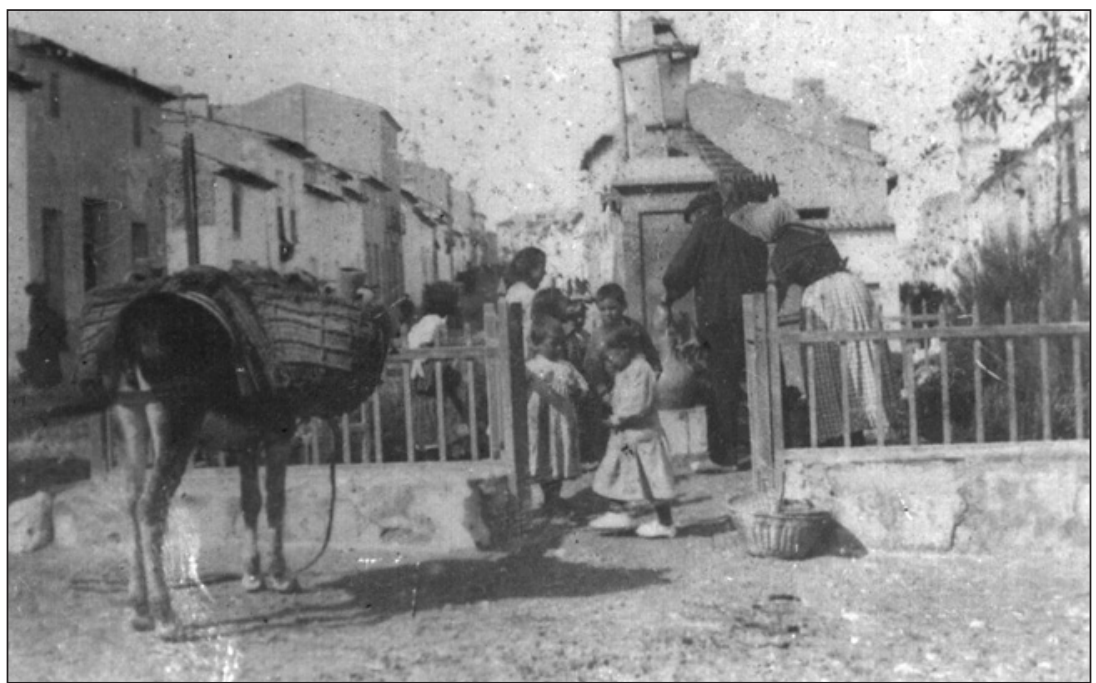

Fuente: Archivo Tani. Año 1945.

\section{UN ESPACIO DE CONTRASTES FÍSICOS}

\section{II.1. Un relieve inmerso en las Cordilleras Béticas}

Desde el punto de vista geológico el espacio objeto de estudio se encuentra ubicado en las zonas externas de las cordilleras Béticas y en ellas se encuentran representados dos dominios tecto-sedimentarios diferentes: Prebético externo y Prebético interno. Las alineaciones montañosas presentan una dirección SW-NE, ello propicia la formación característica de corredores naturales o depresiones intramontañosas, muy bien aprovechadas desde tiempos inmemoriales para la realización de caminos y vías terrestres de comunicación que consti- 
tuyen los grandes ejes de comunicación oeste-este entre las tierras de Castilla La Mancha y la Comunidad Valenciana, así como entre esta última y la vecina comunidad Andaluza en la orientación norte-sur. La altura media presenta una media que oscila entre los 400-600 metros sobre el nivel del mar, apareciendo alineaciones montañosas de una altitud nunca superior a los 1.300 metros.

En el aspecto estructural, el mapa Geológico de España (1:50.000) del I.G.M.E. (Hoja 845 27-33) muestra una serie de fallas en la misma dirección anteriormente indicada. También son muy característicos los pliegues en la misma dirección, generalmente isopacos (aquellos cuyas capas no están estiradas ni rotas), vergentes al NO, aunque a veces pueden presentarse vergencias contrarias por efectos diapíricos o retrocabalgamientos. El diapirísmo es un elemento clave para comprender la estructura aflorando por defecto de la cobertera, una serie de materiales triásicos que albergan cantidad de niveles salinos y de yeso, esta riqueza natural ha dado origen desde tiempos remotos a la explotación de canteras generadoras de materiales constructivos. El aprovechamiento económico viene marcado por la utilización de la roca caliza como material de construcción: arcillas, arenas, yesos o gravas, de hecho la arquitectura tradicional emplea estos elementos constructivos (Fuente La Negra, Magdalena,etc) y actualmente de carbonato cálcico ya que en Enero de 2004 se descubrieron en Yecla una de las reservas mayores de Europa en la denominada Cantera de Rocafuerte II.

Otro elemento físico característico es la formación de glacis, generalmente se encuentran fosilizados, intactos. En ellos tras su oportuna roturación se cultiva la vid, formando generalmente pendientes muy moderadas, Ej: La Decarada, Serral, Salinas,etc. Respecto a los aspectos litológicos aparecen materiales desde época secundaria de las edades geológicas como son los materiales provenientes de la época jurásica, las mayores extensiones de la cobertera terrestre la configuran materiales cuaternarios; los mantos de arroyada difusa y abanicos aluviales se localizan al pie de las sierras y zonas elevadas bastantes kilómetros con pendientes suaves y uniformes (de $3^{\circ}$ a $5^{\circ}$ ).

Desde tiempos inmemoriales, como así lo atestiguan las prospecciones arqueológicas (Ruiz, L.200) aparecen vestigios de una intensa búsqueda de agua con la finalidad de satisfacer las necesidades básicas para la pervivencia, lo que denota que la aridez ha sido una constante en este espacio desde hace milenios y ello ha propiciado por parte de sus habitantes una intensa búsqueda de este elemento.

\section{II.2. Un clima de transición entre el litoral mediterráneo y la meseta manchega}

La altitud y continentalidad han sido rasgos invariables a lo largo de los siglos en este espacio objeto de estudio. Estos factores, junto a la propia dinámica atmosférica, han condicionado la existencia de un clima que contiene escasas precipitaciones anuales, y que a su vez son de gran intensidad horaria y por tanto de marcado carácter torrencial. Prueba de ello es la plasmación en la morfología del territorio de grandes abanicos fluviales, ramblas y barrancos. La torrencialidad de las aguas junto a la existencia de un roquedo fácilmente erosionable y la ausencia de un cobertera vegetal densa, han posibilitado la formación de grandes canales de drenaje o evacuación de aguas, hecho que ha desarrollado en más de una ocasión auténticos paisajes de bad-lands. 
Foto 2

RAMBLA DE JUMILLA

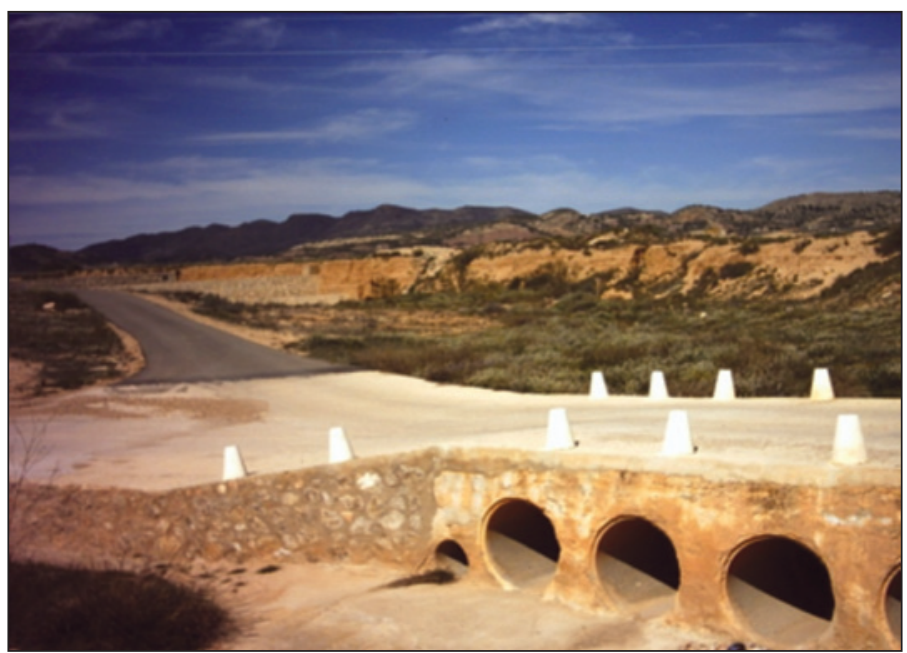

Fuente: F. Morales (2013).

Foto 3

CANALIZACIONES SITUADAS EN EL PARAJE DEL «PULPILLO»

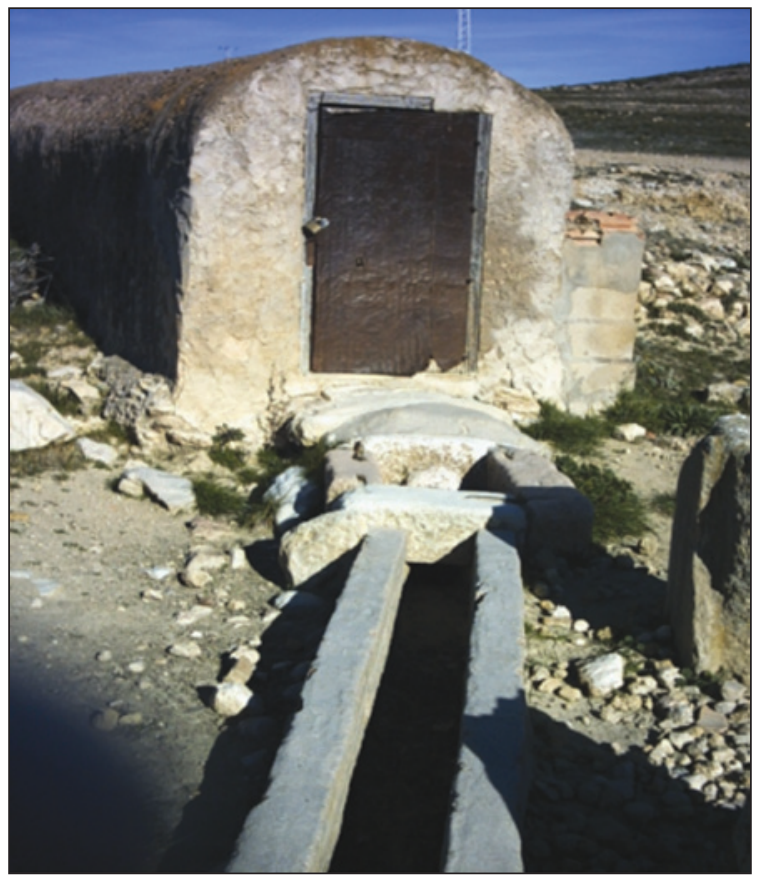

Fuente: F. Morales (2013). 
En todo el término municipal no existe ningún curso de agua permanente; la capacidad de infiltración de la roca caliza, ha repercutido en el almacenamiento de aguas en el subsuelo. Desde tiempos inmemoriales, los seres humanos han debido adaptarse a las rigurosidades de este clima adverso; ante el gran déficit hídrico, el paisaje está plagado de aljibes, pozos, canalizaciones, etc, infraestructuras todas, que sirven para almacenar, captar o conducir los exiguos caudales del agua provenientes del subsuelo, incluso aparecen nombres de algunos parajes que representa un léxico rico en acepciones derivadas del agua tales como los parajes de: Las Artesillas, La Fuente, La Balsa, Baños, Canalizos, Lavaor, etc o nombres de calles en la ciudad como, Rambla, Ramblizo, Muro de los Aguadores, El Agua, etc.

\section{II.3. Precipitaciones escasas y de carácter torrencial}

La media anual de lluvias en Yecla se encuentra en unos $320 \mathrm{~mm} / \mathrm{m}^{2}$, muy baja para las necesidades reales de este ámbito geográfico, la media de días lluviosos al año es de unos veintiséis. En cuanto a las temperaturas, observamos una gran amplitud térmica anual $\left(19,7^{\circ}\right)$. También inciden de manera decisiva las heladas y los fuertes vientos del norte. El conjunto de estos factores configura un ambiente poco halagüeño para la vida humana, al menos en épocas pasadas.

Un rasgo esencial, como anteriormente comentábamos es la aridez, hecho que ha repercutido en un desarrollo de las técnicas de aprovisionamiento de agua por parte de los moradores de estas tierras desde tiempos inmemoriales a través de variadas y sorprendentes técnicas de captación, distribución y almacenamiento como serían: boqueras en las ramblas, embalses, acueductos, norias, pozos, aljibes, etc.

En los estudios realizados (Rodríguez Estrella y otros, 1980), las glaciaciones no llegaron a esta latitud o al menos tuvieron poca intensidad. Sí podemos afirmar la gran potencia de las heladas invernales, que ocasionan en los sectores de mayor altitud procesos de gelivación o diaclasamiento del roquedo, así como la paralización de la vida vegetativa.

A continuación, se presenta un climograma con datos recogidos en la estación de Yecla en el periodo desde 1942-2002 inclusive. Obviando la elaboración de este tipo de diagramas, que resulta compleja y extensa, pasamos directamente a comentar los datos obtenidos, que son bastante representativos. En primer lugar queda señalada la temperatura media, que es la mínima de Enero $\left(5,4^{\circ}\right)$ y la máxima de Julio $\left(25,1^{\circ}\right)$. Respecto a las posibilidades agroclimáticas, pensando en la no existencia de regadíos, observamos que la detención vegetativa por falta de temperaturas, ocupa un periodo de 2,5 meses para las plantas de mayor adaptación, mientras que por falta de pluviosidad es de 3,5 meses (verano). El periodo de excedente hídrico es posible cuando la precipitación mensual es mayor que la E.T.P. (evapotranspiración potencial). En el caso de Yecla, se observa esta posibilidad durante tres meses; los que van desde diciembre a febrero. Las etapas potencialmente vegetativas se dividen en dos periodos que coinciden con la primavera y otoño, la primera con cierto retraso.

Frente al factor de excedente hídrico, otro factor importante es la composición de los suelos, que pueden tener mayor o menor necesidad de agua, así como las plantas de cultivos; también la insolación, periodo libre de heladas, sería de unos 5,4 meses. Los cereales de secano presentan posibles problemas hídricos y su mayor rigor estival favorece la producción de plantas termófilas (aquéllas que resisten bien el calor). Es muy recomendable, debido 
a la falta de precipitaciones, la instalación de regadíos, este hecho aumenta considerablemente la rentabilidad de las tierras, aunque también ha traído consecuencias negativas como la sobreexplotación de los acuíferos y peligro de salinización de suelos.

Figura 1

CLIMOGRAMA DE YECLA

CLIMOGRAMA DE GAUSSEN

Yecla C.H. Segura

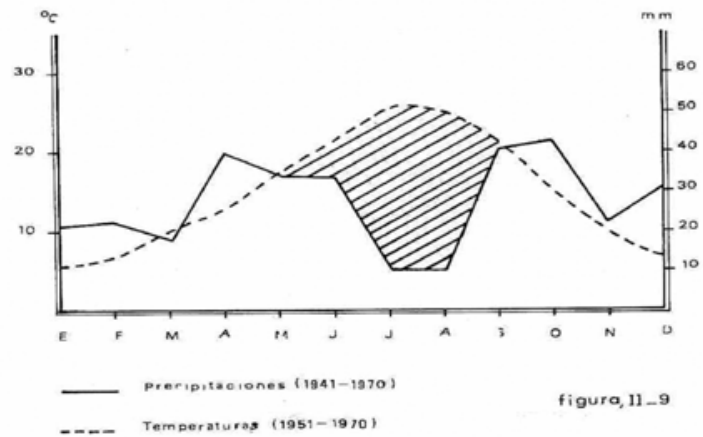

Fuente: Confederación Hidrográfica del Segura.

\section{PROPUESTAS PARA CONSOLIDAR UN DESARROLLO SOSTENIBLE EN YECLA EN RELA- CIÓN A LOS RECURSOS HÍDRICOS EXISTENTES}

\section{III.1. Necesidad de una adecuada mentalización ciudadana en relación al consumo del agua}

Como anteriormente comentábamos el Sureste español padece una crónica y profunda escasez natural de recursos hídricos motivada por factores de orden climático, hidrográfico e hidrogeológico (Rico Amorós, 2002). El déficit hídrico es únicamente compensado por las aguas extraídas del subsuelo ya que no se registra ningún aporte externo alguno. En relación al espacio objeto de estudio en el año 2000, la empresa Enviros-Cuantisci, realizaba por encargo del Ayuntamiento de Yecla un estudio sobre los recursos hídricos del término municipal de Yecla. En su presentación ante los medios de comunicación, el geólogo Jordi Guimerá, técnico redactor del estudio indicaba en las conclusiones, con respecto al estado de nuestros acuíferos que la situación no era «alarmante» pero si preocupante.

Señalaba que en la zona alta del término municipal (carretera de Montealegre-Fuenteálamo), el descenso del nivel de acuíferos era menor que en la zona baja (Sierra de SalinasRaspay). Después de estudiar la evolución de la recarga natural de nuestros acuíferos desde el año 1968 al 1998, en base a datos de precipitaciones y temperaturas, Guimerá indicaba que anualmente se producía una recarga media de 18 hectómetros cúbicos de estos acuíferos. Se apreciaba que todos los años se realizaba un consumo medio estimado de $0,3 \mathrm{hm}^{3}$ para consumo industrial, $2 \mathrm{hm}^{3}$ en el consumo urbano y unos $24 \mathrm{hm}^{3}$ año para usos agrícolas. 


\section{Gráfico $n^{0} 1$ \\ DISTRIBUCIÓN DEL CONSUMO DEAGUA EN YECLA POR ACTIVIDADES}

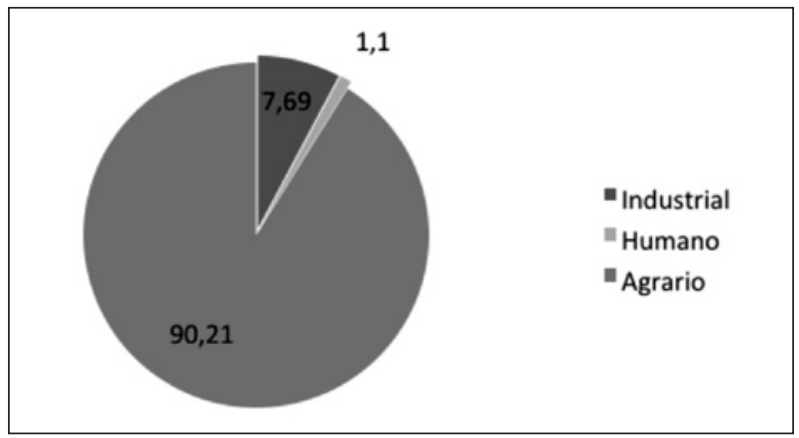

Fuente: Jordi Guimerá y Elaboración Propia

La causa principal de este excesivo consumo agrícola parece encontrarse en que durante estos últimos años se ha producido una notable implantación de explotaciones agrarias de regadío en zonas tradicionales de secano o de regadíos extensivos y por supuesto la pertinaz sequía, lo que ha derivado en una mayor necesidad de agua y sobreexplotación de los acuíferos. Jordi Guimerá concluía señalando que el déficit hídrico anual en el término municipal era de unos $10 \mathrm{hm}^{3}$. En base a estos datos, en los cinco años existentes a la realización de este estudio (2001-2006), no era grave para él. Pero a más largo plazo, consideraba que el consumo agrícola llevaría a comprometer el consumo industrial y urbano.

Hemos extraído datos del término municipal de Yecla, observando cómo las tierras dedicadas al cultivo experimentaron su mayor índice en 1972, un total de 54.859 Hectáreas estaban cultivadas ese año, lo que suponía de las 60.774 Has. de las que tiene el total del término municipal, lo que vendría a ser el 90,26\%. En la década de los ochenta el abandono de tierras fue evidente, el principal factor era la entrada de España en el año 1986 en la entonces Comunidad Económica Europea, la reestructuración del viñedo y cuotas de cereal repercutió en el abandono de las tierras menos fértiles, en 1989 el porcentaje de tierras cultivadas había descendido al 76,44\%. Los datos actuales indican una fase de ligero ascenso, $79,77 \%$, aunque el dato más importante no sería el aumento de superficie cultivable, más bien, hablaríamos del interés por convertir las tierras de secano en regadío, con el consiguiente aumento de las producciones, llegada de nuevos cultivos y por tanto mayo generación de riqueza.

Por supuesto la adopción de otras medidas como el riego localizado por goteo son imprescindibles y se van extiendo lentamente por su elevado coste de instalación, así como la construcción de grandes balsas de riego que al no estar techadas pierden ingentes cantidades de agua por evaporación en la época estival, cuestión que continúa sin solucionarse.

Es necesaria por tanto una reflexión, no se puede seguir creciendo en tierras de regadío con el agua existente actualmente, ya que no solamente se pone en peligro la riqueza agrícola, también el abastecimiento de la población y de los espacios industriales que afortunadamente son poco consumidores de agua. 


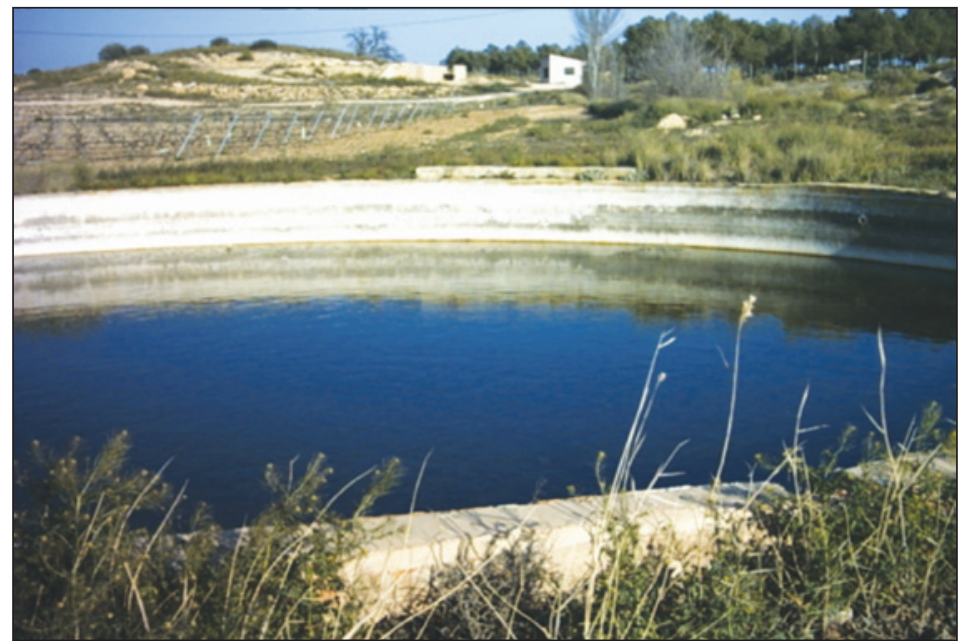

Fuente: F. Morales (2013).

La educación para consumir bien y no caer en el consumismo es difícil en una sociedad como la nuestra que debe mentalizarse totalmente sobre las repercusiones que conlleva el consumo excesivo, así como de las medidas necesarias para ser austeros y que ello se interiorice en la población, se calcula que el municipio de Yecla dispone de unos $1840 \mathrm{~m}^{3 /}$ habitante /año, muy inferior por tanto a los $2829 \mathrm{~m}^{3} /$ habitante /año de la media española y a los 3100 de la Unión Europea (López, 2000), a pesar de esta escasez el precio del agua es bajo, ello contribuye a que el llenado/vaciado en verano de las cientos de piscinas extendidas por todo el término municipal sea en los casos más extremos quincenal, ya que es más económico cambiar el agua que utilizar productos que la conserven más tiempo, aunque hay que reconocer que está creciendo el número de propietarios que cada vez cuidan más en agua con productos e incluso que pasan dos o tres años con la misma agua, también en el aspecto normativo se contemplan sanciones por el vaciado de las piscinas sin haber cumplido el plazo preceptivo.

Respeto al planteamiento. antes de la llegada de la crisis económica de 2008 a nuestros días, de posibles construcciones campo de golf en la zona, sería conveniente que en este tipo de iniciativas se tenga muy en cuenta la procedencia del agua, por ejemplo de reciclado, nunca con aguas procedentes directamente de los acuíferos, quedando garantizado un adecuado y racional suministro. Urge por tanto entre otras medidas la realización de campañas de información, control de consumo con sus correspondientes sanciones. En la Región de Murcia en 2013 existen en uso un total de doce campos de golf, todos se riegan con aguas reciclada o desaladas, cumpliendo la normativa al respecto aunque también el expresidente de la Confederación Hidrográfica del Segura, Sr. Fuentes Zorita declaró que «Es legal regar campos de golf con pozos agrícolas si se le concede el permiso de cambiar el uso del agua. No afecta a la sequía, porque realmente gasta más agua un campo de lechugas que uno de 
golf. Además, a ningún agricultor le ha faltado agua en época de sequía. El problema es controlar a las promotoras que riegan de forma fraudulenta, sin tener autorización, como el caso del campo de golf de La Peraleja, de Sucina. Todo empieza por dar licencia municipal para hacer un campo de golf sin tener garantizado el suministro del agua». La importancia de la depuración de las aguas residuales para la utilización en los campos de golf en Murcia queda perfectamente reflejada en el artículo de Espejo Marín (2004).

Otra cuestión es la ordenación y mejora en el uso de los recursos hidráulicos, recordemos que los gastos de agua descienden mucho cuando el sistema de regadíos es adecuado, aunque ello exija de entrada mayores inversiones en equipamientos, todavía se utilizan los riegos a manta, aunque es digno reconocer que el esfuerzo de los agricultores ha sido muy meritorio en todo el término municipal con la instalación de riego por goteo y aspersión. También el control de regadíos ilegales o la posible creación de los mismos. Por último otro aspecto destacable que puede afectar el uso del suelo es la utilización de productos fitosanitarios que puedan dañar el subsuelo, una alternativa posible es el incremento de la agricultura ecológica, poco extendida de momento en el término municipal.

Cuadro $n^{0} 1$

CONSUMO DE AGUA SEGÚN SISTEMA DE RIEGO

\begin{tabular}{|l|l|}
\hline Sistema de riego & Consumo aproximado \\
\hline A manta o inundación (tradicional) & 30 litros por segundo \\
\hline Aspersión & 15 litros por minuto \\
\hline Goteo o localizado & $4 / 6$ litros por hora \\
\hline
\end{tabular}

Fuente: CEMA «Los Molinos» Crevillente.

\section{III.2. Mejora en el saneamiento de la red de abastecimiento y calidad de las aguas}

Es necesaria por parte de las autoridades públicas un plan continuado de mejoras en la red de suministro urbano, puesto que la red se halla envejecida en diversas partes de la ciudad, presentando constantes pérdidas y perjuicios en la circulación por la interrupción por obras, de hecho las constantes fugas han provocado que el callejero sufra periódicamente parcheados en el asfalto por roturas constantes.

Dadas las condiciones del trazado urbano, en el piedemonte del Cerro del Castillo, la evacuación de aguas a través de la red de Alcantarillado no presenta ninguna incidencia ya que existe un gran desnivel lo cual beneficia el desalojo de las aguas pluviales de forma rápida. Tampoco se detectan en la ciudad focos de malos olores ni retenciones, con el Plan de recuperación del casco viejo se están corrigiendo estos problemas (calles Parra, Olivo, Granada, Rosa, etc.)

Se observa en el mapa de abastecimiento de Yecla, la procedencia desde el Cerro de la fuente y la distribución del agua en el casco urbano y área del Polígono Industrial urbayecla I y II. La red es compleja y extensa ya que se extiende hacia el área periurbana a través de tuberías. También destacamos en el transporte del agua diferentes tipos de infraestructuras según su capacidad de transporte. 


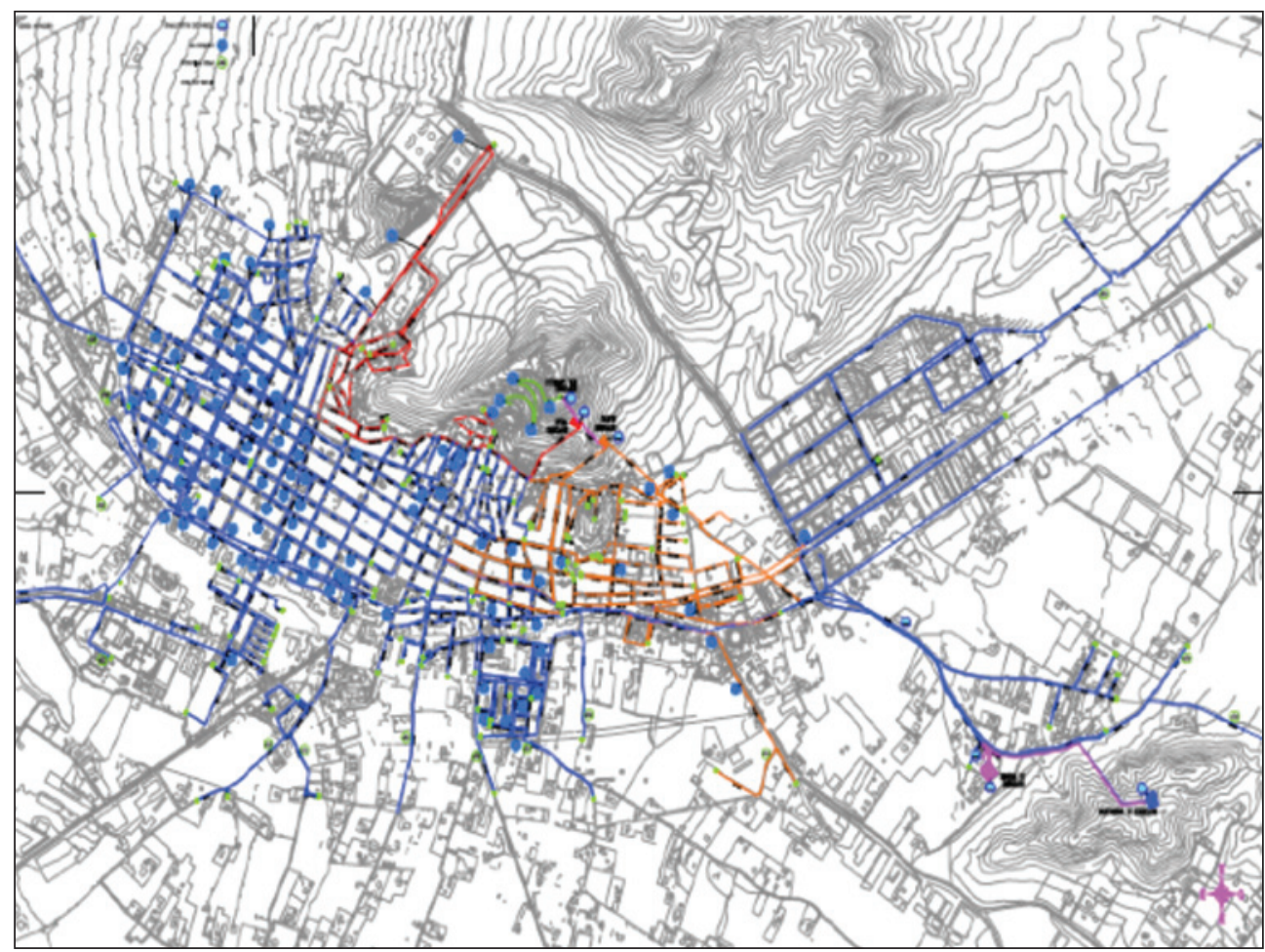

Fuente: Ayuntamiento de Yecla y elaboración propia.

En relación a la calidad del agua, la historia de los primeros estudios analíticos ha quedado estudiada por D. Fernando López Azorín a través de sendos artículos publicados en la Revista de estudios locales «Yakka» no 13 (pp.151-164)-año 2003- y nº 14 (pp. 147-165) -año 2004-. En estos trabajos se dan a conocer los primeros trabajos relacionados con la calidad del agua en Yecla, efectuados por los Padres Escolapios, D. Manuel Gómez Peña y D. Ángel Vinagre Alonso entre los años 1874-1878. También se publica un resumen de los trabajos del farmacéutico D. José Azorín Fornet en el primer tercio del siglo XX.

Las conclusiones de estos estudios señalan que las aguas de Yecla son variadas de unos manantiales respecto a otros, de forma general se habla de «aguas excesivamente calizas y alto componente en magnesio y sulfatos, con una dureza total que generalmente se aproxima, o incluso supera los límites del máximo legal para su potabilidad, ya que se encuentran por encima de $40^{\circ}$ hidrotimétricos, aunque el margen normal es de 30-40 ${ }^{\circ}$. Por ejemplo tenemos la Casa Potra $\left(31^{\circ}\right)$, Fuente del Pinar $\left(33^{\circ}\right)$, Las Pansas $\left(34^{\circ}\right)$. También la salinidad es un factor a destacar; Fuente del Lobo (32 $)$, Marisparza $\left(35^{\circ}\right)$ y Pozo artesiano del Rasillo $\left(40^{\circ}\right)$. Finalmente en este trabajo se destaca el problema de las conducciones, hecho que determina en diferentes casos la aparición de gérmenes o microbios, por ejemplo el uso de tubos de 
uralita perjudica notablemente la potabilidad del agua. Recomendamos al lector la lectura de estos artículos de López Azorín para conocer la historia analítica de las aguas de Yecla en el pasado, también Soriano Torregrosa en su libro «Historia de Yecla» (pp.195-197) realiza una breve mención a la calidad de las aguas de Yecla, realizando una comparación con las agua de Virtus (Burgos) señala que «De ningún nacimiento del término, al parecer, surgen aguas potables. Desde luego, se consumen en otros sitios aguas todavía con un grado de potabilidad inferior. Pero, comparadas con las aguas norteñas, excelentemente potables, la de Yecla dejan bastante que desear, aunque sean de las mejores de las zonas próximas». Alude Soriano Torregrosa a las analíticas realizadas por D. Manuel Gómez en 1880, publicadas en el Semanario Murciano y también por el farmacéutico de la localidad D. Antonio Torregrosa Ibáñez, en ambos casos se destaca el alto grado hidrométrico.

A continuación nos interesa como información nueva en este estudio presentar el estado actual de las aguas de la ciudad, para ello nos centraremos en la Fuente Principal de Yecla y Raspay. Los datos que presentamos en el siguiente cuadro están analizados en 2007 y señalan unos parámetros normales para tranquilidad de los ciudadanos, por ejemplo los índices máximos que supondrían peligro, según normativa (BOE 20-09-1990) señalan para los cloruros $200 \mathrm{mg} / \mathrm{l}$, sulfatos $250 \mathrm{mg} / \mathrm{l}$, calcio $100 \mathrm{mg} / \mathrm{l}$, magnesio $50 \mathrm{mg} / \mathrm{l}$, nitratos $25 \mathrm{mg} / \mathrm{l}$, nitritos 0,1 $\mathrm{mg} / \mathrm{l}$, amonio $0,5 \mathrm{mg} / \mathrm{l}$.

Cuadro $n^{\circ} 2$

ANÁLISIS DE LAS AGUAS DE YECLA

\begin{tabular}{|c|c|c|c|c|c|c|c|c|c|c|c|c|c|}
\hline Nombre & $\mathrm{Ph}$ & $\begin{array}{c}\text { Condu } \\
\text { Tividad } \\
\mathrm{uS} / \mathrm{cm}\end{array}$ & Cloruros & $\begin{array}{c}\text { Sulfatos } \\
\mathrm{mg} / \mathrm{l}\end{array}$ & $\begin{array}{c}\text { Calcio } \\
\mathrm{mg} / \mathrm{l}\end{array}$ & $\begin{array}{c}\text { Magnesio } \\
\mathrm{mg} / \mathrm{l}\end{array}$ & $\begin{array}{c}\text { Dureza } \\
\mathrm{mg} / \mathrm{l}\end{array}$ & $\begin{array}{c}\text { Nitratos } \\
\mathrm{mg} / \mathrm{l}\end{array}$ & $\begin{array}{c}\text { Nitritos } \\
\mathrm{mg} / \mathrm{l}\end{array}$ & $\begin{array}{c}\text { Amonio } \\
\mathrm{mg} / \mathrm{l}\end{array}$ & $\begin{array}{c}\text { Oxidacion } \\
\mathrm{mg} / \mathrm{l}\end{array}$ & $\begin{array}{c}\text { Cloro } \\
\mathrm{mg} / \mathrm{l}\end{array}$ & $\begin{array}{c}\text { Cloro T. } \\
\mathrm{mg} / \mathrm{l}\end{array}$ \\
\hline $\begin{array}{c}\text { Fuente } \\
\text { Yecla }\end{array}$ & 7,9 & 700 & 61 & 124 & 65 & 39,9 & 32,6 & 11,9 & $<0,1$ & $<0,1$ & 0,8 & 0,58 & 0,58 \\
\hline Raspay & 7,8 & 620 & 65 & 51 & 54 & 35,7 & 28,1 & 6,1 & $<0,1$ & $<0,1$ & $<0,8$ & 0,4 & 0,43 \\
\hline
\end{tabular}

Fuente: Soriano Sánchez, D. 2013.

Respecto a la presencia de minerales, también los índices se encuentran dentro de los parámetros para el consumo humano. No se detectan ningún tipo de enterococos, leginonella, coliformes o clostridium.

Cuadro $n^{0} 3$

ANÁLISIS DE LAS AGUAS DE YECLA. (MINERALES)

\begin{tabular}{|c|c|c|c|c|c|c|c|c|c|c|c|c|c|}
\hline Nombre & $\begin{array}{c}\text { Minio } \\
\mathrm{ug} / \mathrm{l}\end{array}$ & $\begin{array}{c}\text { Boro } \\
\mathrm{ug} / \mathrm{l}\end{array}$ & $\begin{array}{c}\text { Cobre } \\
\mathrm{ug} / \mathrm{l}\end{array}$ & $\begin{array}{c}\text { Mercu } \\
\text { Rio } \\
\mathrm{ug} / \mathrm{l}\end{array}$ & $\begin{array}{c}\text { Hierro } \\
\mathrm{ug} / \mathrm{l}\end{array}$ & $\begin{array}{c}\text { Plomo } \\
\mathrm{ug} / 1\end{array}$ & $\begin{array}{c}\text { Cadmio } \\
\mathrm{ug} / \mathrm{l}\end{array}$ & $\begin{array}{c}\text { Selenio } \\
\mathrm{ug} / \mathrm{l}\end{array}$ & $\begin{array}{c}\text { Cromo } \\
\mathrm{ug} / \mathrm{l}\end{array}$ & $\begin{array}{c}\text { Niquel } \\
\mathrm{ug} / \mathrm{l}\end{array}$ & $\begin{array}{c}\text { Manga } \\
\text { Neso } \\
\mathrm{ug} / \mathrm{l}\end{array}$ & $\begin{array}{c}\text { Arse } \\
\text { nico } \\
\mathrm{ug} / 1\end{array}$ & $\begin{array}{c}\text { Antimonio } \\
\mathrm{ug} / 1\end{array}$ \\
\hline $\begin{array}{c}\text { Fuente } \\
\text { Yecla }\end{array}$ & 104 & 0,16 & $<5$ & 0,31 & $<20$ & 0,55 & $<0,5$ & $<2$ & $<1$ & $<2$ & $<5$ & $<2$ & $<0,5$ \\
\hline Raspay & $<20$ & 0,11 & $<5$ & 0,63 & $<20$ & $<0,5$ & $<0,5$ & $<2$ & $<1$ & $<2$ & $<5$ & $<2$ & $<0,5$ \\
\hline
\end{tabular}

Fuente: Soriano Sánchez, D. 2013. 
En definitiva la calidad de las aguas de Yecla se considera de tipo medio, como factores más negativos estarían su tendencia a la calcificación y dureza, de hecho de todos es conocido el problema de la cal en electrodomésticos y calderas, así como en el caso de problemas de salud como puedan ser la aparición de litiasis renal, también denominada urolitiasis o nefrolitiasis que es una enfermedad causada por la presencia de cálculos o piedras en el interior de los riñones o vías urinarias (uréteres, vejiga).

\section{III.3. Eficacia en la gestión de aguas residuales y aumento del reciclaje ante las demandas futuras}

El casco urbano esta abastecido por el denominado «pozo de la Fuente», en la actualidad no existe ningún tipo de problemas en cuanto al abastecimiento de agua a corto plazo, pero los descensos piezométricos continúan (en el año 2013, el nivel de extracción se sitúa a 81 metros de profundidad, recordemos que en el año 1972 el nivel se situaba en 37 metros), aunque de forma anecdótica el día 16 de febrero de 2007 los técnicos se llevaron un gran susto ya que el nivel descendió en unas pocas horas hasta los 102 metros de profundidad, recuperándose al día siguiente, los técnicos señalaron que pudo ser debido por un derrumbe interno (El periódico de Yecla)

De todas maneras y aunque lentamente es un hecho constatado de que los niveles continúan descendiendo, sirva el ejemplo del año 2002, que fue bastante lluvioso y la recuperación del acuífero no se manifestó. Ante esta problemática el Ayuntamiento decidió (Julio 2002) «efectuar una serie de inversiones para mejorar los equipos de bombeo, porque los existentes tenían una capacidad de profundidad determinada». De este pozo se abastece a la población de Yecla, más de 35000 personas, así como instalaciones urbanas e industriales, ello supone una extracción diaria de 8500 metros cúbicos, en un año se extraen 3,1 hectómetros cúbicos para el consumo humano.

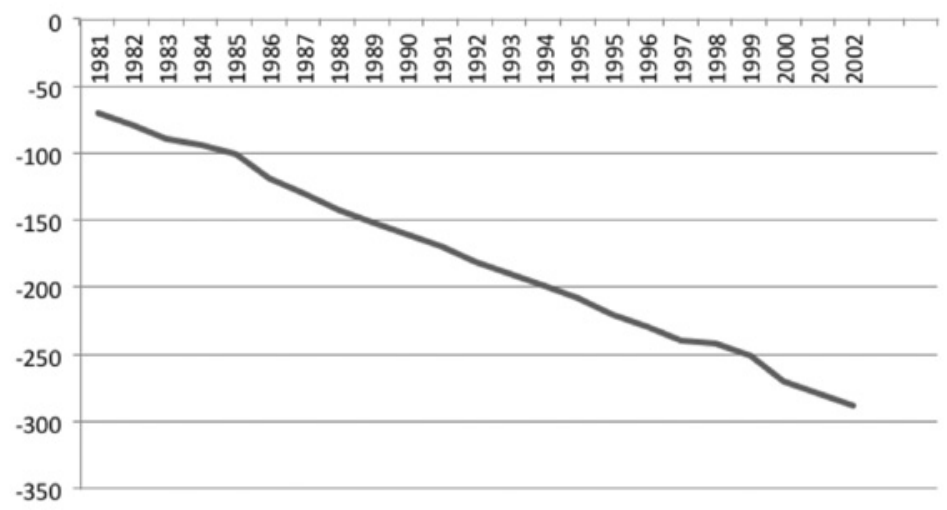

Fuente: Elaboración Propia y web: www.aguacam.com/materiales/pdf/nuevas_visiones/11a.pdf 


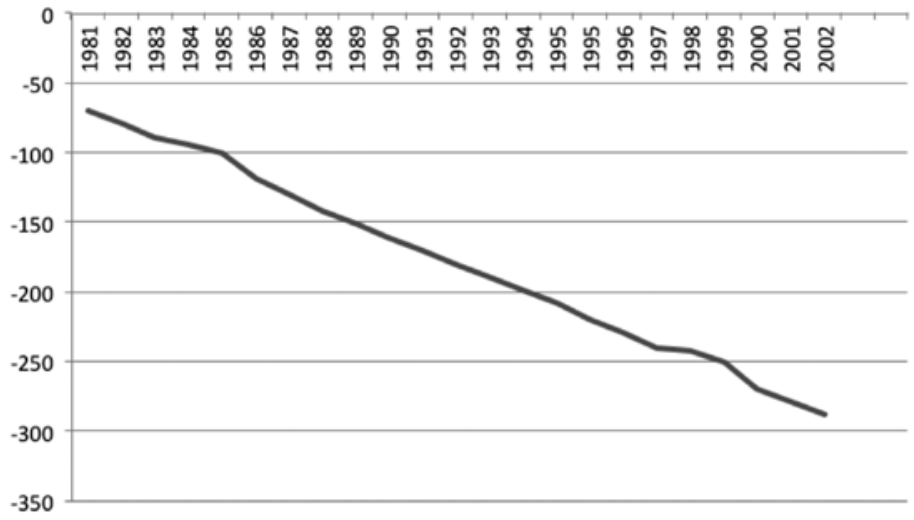

Fuente: Elaboración Propia y web: www.aguacam.com/materiales/pdf/nuevas_visiones/11a.pdf

Se trata de una solución a corto plazo ya que la cuestión viene determinada por el enorme aumento de agua que se está realizando en las tareas agrícolas con los nuevos cultivos de temporada implantados en la ciudad en la dos últimas décadas, fruto por supuesto de una economía rural voraz de exportación de productos extratempranos muy bien acogidos y pagados en los países de la U.E. Se plantea la cuestión entre desarrollo económico y agotamiento de los acuíferos. La solución tal como indica el propio representante municipal pasaba por la puesta en marcha del derogado Plan Hidrológico Nacional (2004) y la llegada de agua del trasvase del Ebro ya que en la comarca de Yecla no existen otros aportes hídricos que los generados por el agua de lluvia al infiltrarse y recargar los acuíferos.

Respecto al tratamiento de aguas residuales la depuradora municipal instalada en el Paraje del Camino de Sax (Cañada Morcillo) a unos $2 \mathrm{Kms}$. de Yecla tiene capacidad suficiente en condiciones normales para alcanzar un grado de depuración del $95 \%$ lo que significa un vertido de aguas depuradas de $1,5 \mathrm{Hm}^{3}$. Al día tiene capacidad para depurar unos $5000 \mathrm{~m}^{3}$ por el denominado sistema de lagunaje. Esta depuración es reinvertida en agua para riegos a través de la Comunidad del Pozo de Santiago, también se destina una parte de la depuración a la fabricación de abonos. La cuestión viene dada por la producción de olores, un problema de difícil solución por las propias características del trabajo efectuado, han sido muchísimas las actuaciones de las distintas corporaciones para subsanar este déficit; instalaciones de turbinas, centrifugadora de fangos, etc, y está claro que «es comprensible que siempre se genere algo de olor».

La cuestión en este caso es patente que olores aunque sea mínimos van a existir, quizás en su momento se podría haber considerado la ubicación de esta planta que tan enormes inversiones ha supuesto en un lugar más alejado del casco urbano, recordemos que su ubicación está a menos de $1 \mathrm{Km}$. en línea recta del complejo de la carretera de Villena, en donde existen actualmente numerosas exposiciones de muebles, varios restaurantes y locales de carácter comercial y de ocio. Desde el punto de vista geográfico, la implanta- 
ción de la depuradora en su entorno inmediato supuso la paralización de construcciones, sobre todo de casas de campo, tan habituales en la zona, también han quedado inutilizada las antiguas balsas de contención que convendría ocultarlas ya que su impacto visual en el camino de Sax es importante.

Otra cuestión importante, todavía insuficientemente estudiadas serán en el futuro las posibles consecuencias del cambio climático en nuestras latitudes, según los últimos estudios realizados, las sequías y aumento de calor serán progresivos, aumentando por tanto el riesgo de desertificación preexistente (Romero, 2009). Ante estas previsiones de futuro es urgente tomar medidas en el presente para paliar en la medida de lo posible las consecuencias futuras.

El cambio climático está teniendo ya fuertes efectos y a un ritmo mucho mayor de lo previsto en los ecosistemas, los recursos hídricos y las zonas costeras de todo el mundo y puede llevar a la desaparición de más del $30 \%$ de las especies animales y vegetales del planeta, según se desprende del segundo informe de grupo intergubernamental de expertos de Naciones Unidas, señalan que los seres humanos están ya padeciendo las consecuencias del calentamiento global citando, por ejemplo, el aumento de las tensiones provocadas por la falta de agua. Uno de los factores que emerge con más fuerza en buena parte del mundo pero sobre todo en la zona del Mediterráneo serán los problemas del agua. Así, la ONU calcula que para finales de siglo XXI los problemas de abastecimiento de agua en Europa podrán afectar a unos 50 millones de personas y buena parte de esos problemas se producirán en las cuencas del Sur y del Este y centro de Europa.

Según este informe para el caso de España los efectos de una eventual subida de la masa de agua en los mares y océanos podría afectar a tres zonas esencialmente; el Delta del Ebro, Doñana y el Mar Menor. Evidentemente esta subida de niveles marinos poco podrá afectar desde el punto de vista físico de invasión de aguas al espacio geográfico del área que estudiamos, ya que Yecla se encuentra a unos 600 metros de altitud. Otras cuestiones en la que sí nos veremos envueltos de lleno si se cumplen las previsiones de los científicos serán el aumento de sequías y por consiguiente las dificultades para el abastecimiento humano, industrial y agrícola, todos ellos de suma importancia en el desarrollo de este espacio geográfico. También se contemplan otros aspectos que afectan plenamente como serán la posibilidad de mayores riadas e incremento del calor ambiental, aspectos que afectarán a la biodiversidad e incluso la salud por las olas de calor.

Ante este panorama de futuro, urge que las autoridades y ciudadanía en general nos concienciemos de lo que está sucediendo para paliar lo máximo las consecuencias futuras de lo que parece un cambio climático irremediable.

\section{III.4. Posibilidades en la captación de recursos hídricos externos: trasvases y desaladoras}

La llegada al gobierno de España del PSOE tras las elecciones de marzo de 2004 supuso un cambio de orientación en la política hídrica de España, en primer lugar se derogó el trasvase del Ebro apostando hacia otras iniciativas para frenar el déficit de agua, centrándose esencialmente en la puesta en la creación de plantas desalinizadoras con el denominado programa A.G.U.A.

La puesta en marcha de este programa proponía una serie de actuaciones en la Región de Murcia de importante calado, la cuestión es que diez años después, el nivel de ejecu- 
ción de estas infraestructuras ha sido poco ejecutado y referente a esta comarca el nivel de actuaciones no ha comenzado, la llegada de agua a través de los canales del Taibilla era la propuesta de la Confederación que se encuentra completamente paralizada dadas las dificultades existentes en las aportaciones realizadas a través del trasvase Tajo-Segura, en donde el actual gobierno del Partido Popular no termina de concretar la continuidad futura de dicho trasvase, el cual recordamos ha sido desde su puesta en marcha en 1979 la mayor actuación hidráulica en nuestro país, transformando un profundo cambio socioeconómico en el SE español, con una superficie total de riego de $132.723 \mathrm{Ha}$, un volumen de $400.000 .000 \mathrm{~m}^{3} /$ año y unos 44.000.000 de árboles frutales (Confederación Hidrográfica del Segura, 2013).

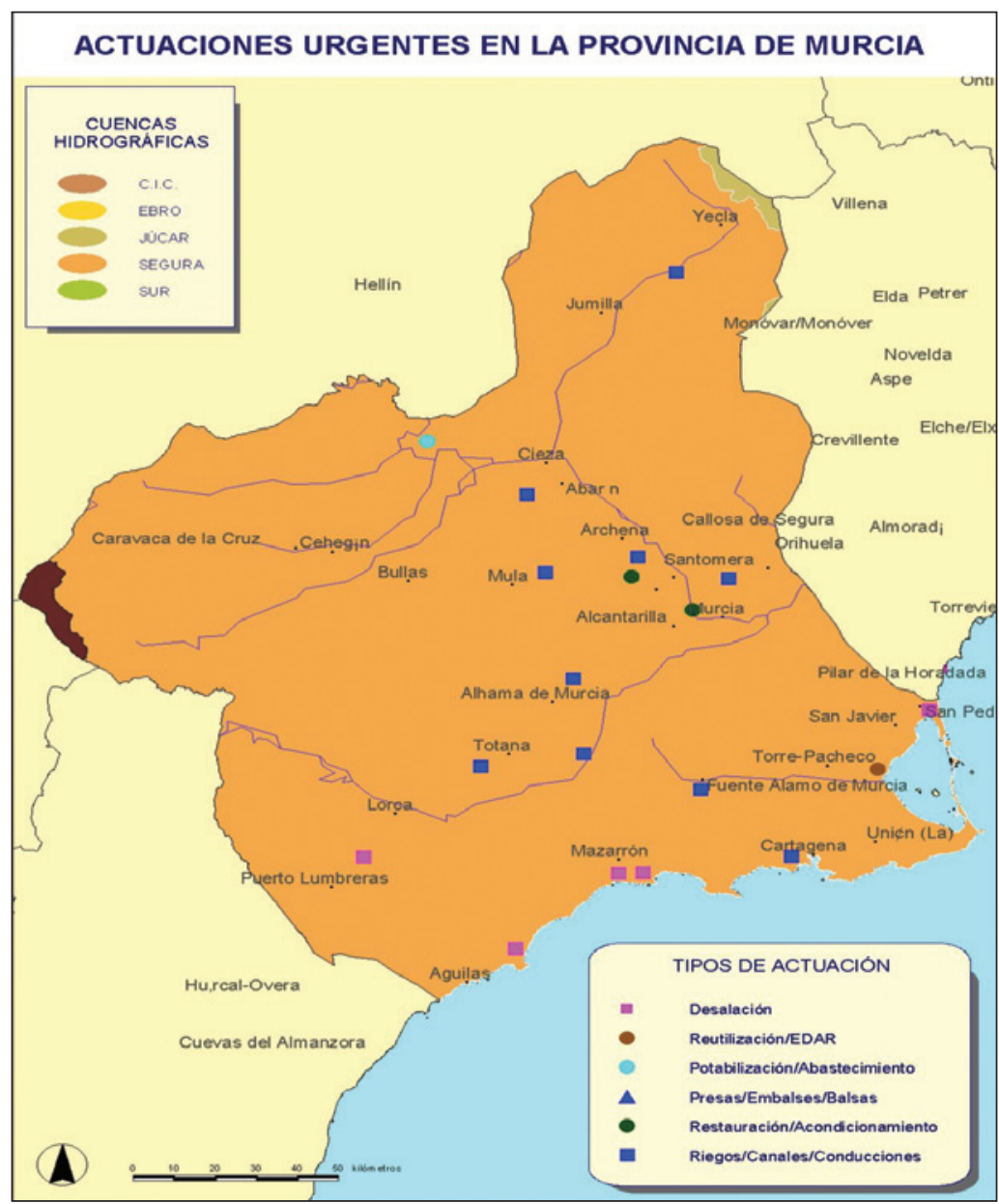

Fuente: Programa A.Q.U.A. Ministerio de Medio Ambiente. 
La llegada del agua del trasvase del Ebro a la comarca de Yecla, habría posibilitado el inicio de la recarga de los acuíferos así como el cambio y aumento de cultivos dedicados a la exportación en el mercado europeo, que para determinados productos extratempranos es muy consumidor. Por tanto se habría contribuido a la generación de riqueza, creando más puestos de trabajo y el mantenimiento del sector agrario en la ciudad, tan relegado con el gran florecimiento de la industria del mueble implantada en la misma. De hecho el exalcalde de Yecla, Vicente Maeso Carbonell en declaraciones; «Se mostraba muy satisfecho por la noticia» y llegó a afirmar en diversos medios de comunicación que «se trataba de la noticia más importante que ha recibido en los años que llevaba de Alcalde»

PROYECTO DEL TRASVASE DEL EBRO HACIA EL LEVANTE ESPAÑOL

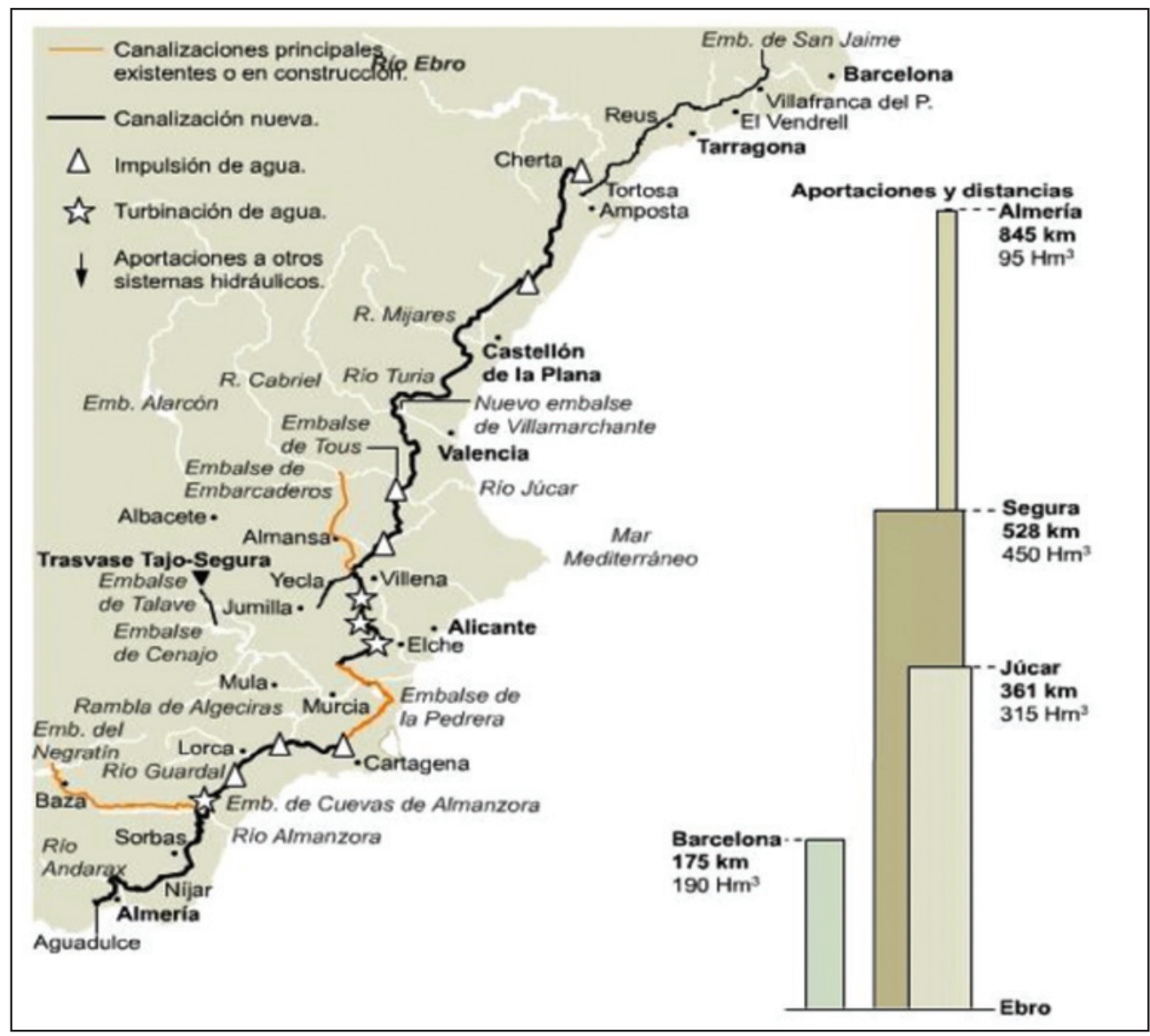

Fuente: PHN.

La aplicación del Plan Hidrológico Nacional, y como hecho puntual la llegada de agua desde la desembocadura del Ebro, era una posibilidad, no única, para que esta zona del SE 
español en cuanto a su desarrollo económico continuara creciendo debido a la extensión de cultivos de regadío y también quedara asegurado el propio abastecimiento de las ciudades, otra cuestión bien diferente sería el uso del agua para un modelo de desarrollo basado en la construcción de urbanizaciones en donde la sostenibilidad de las mismas era dudosa no solamente respecto al abastecimiento de agua, también al propio atractivo de las mismas respecto a su localización con residencias secundarias.

Las controversias de la política han hecho que el sentimiento de solidaridad entre las CC.AA. se haya difuminado, e incluso ha servido de motivo para el enfrentamiento, cuando debía haber sido al contrario, la búsqueda de complementariedad para que ningún territorio salga perjudicado debía haber sido el hilo conductor de la política en materia de agua, teniendo también en cuenta que el ahorro de unos no podía ser motivo de derroche por parte de los otros y viceversa.

La aplicación del PHN no era sólo una ley de trasvases, hecho que sólo afectaba a un $1 \%$ del Balance hidráulico nacional y ha resultado ilógico que este $1 \%$ haya primado sobre el 99\% de los restantes recursos superficiales. La ocasión debería haberse aprovechado para fomentar un Plan Nacional Integral de riegos y la interacción del uso del agua para sus diferentes usos; (abastecimientos urbanos, producción de energía, ocio, industria o temas medioambientales como recarga de zonas lacustres, acuíferos, etc). Tampoco deberían haber repercutido todas las demandas de agua necesarias en el Levante y Sur español sobre el río Ebro, aunque era el elemento más importante por su capacidad hidrológica, tal como propone el profesor Morales Gil (2000).

\begin{tabular}{|c|c|}
\hline Duero Alto (Por el Ebro) & $\ldots 100 \mathrm{Hm}^{3}$ \\
\hline 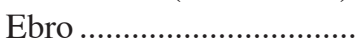 & $\ldots 648 \mathrm{Hm}^{3}$ \\
\hline 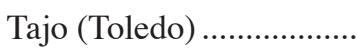 &. $.300 \mathrm{Hm}^{3}$ \\
\hline Guadalquivir (Negratín) . & ... $50 \mathrm{Hm}^{3}$ \\
\hline Total & $1098 \mathrm{Hm}^{3}$ \\
\hline
\end{tabular}

Fuente: Morales Gil, A (2000).

Otra cuestión que no podemos dirimir, es la existencia de suficiente viabilidad económica en el uso de agua desalada para el caso de Yecla y su comarca. El término municipal tiene una altura media sobre el nivel del mar por encima de los 600 metros y por otro lado la costa alicantina, la más cercana queda a más de 80 kilómetros de distancia, y aunque no deberían confundirse la política con los intereses económicos de una comarca, el litoral alicantino no se corresponde con la Comunidad Autónoma a la que pertenece Yecla, la Región de Murcia, cuyo litoral más próximo es San Javier, a más de 160 kilómetros de Yecla.

Técnicamente es posible traer agua desalada a Yecla, económicamente es muy difícil, ya que el proceso de desalación, transporte y distribución supone unos elevados costes 
económicos que harían poco viable el cultivo agrícola por falta de competitividad al imputar los costes del agua, por otro lado también el consumo humano e industrial serían muy elevados. Evidentemente se podrían buscar subvenciones para equiparar el elevado precio del agua, pero ello se verá en el futuro, lo evidente es que ante una economía competitiva el transporte de agua desalada a Yecla es actualmente inviable por el disparatado desembolso económico, recordemos que el coste medio del metro cúbico de agua del mar desalada por el procedimiento de osmosis inversa, situado en la cota Cero, es de 0,4955 Euros.

Esta agua permeada habría que conducirla por elevación y a través de tuberías de presión a las zonas de aplicación del agua y dada la situación de Yecla a más de 80 kilómetros del mar (costa de Alicante-Urbanova) y a más de 600 metros de altitud sobre el nivel del mar, el coste medio del metro cúbico de agua permeada puesto en las zonas regables, será superior a un euro, precio inviable para los cultivos de la zona que no podría competir con otros espacios con mayores facilidades económicas para la obtención de agua (Beloqui Gutiérrez, L. 2004). De todas maneras este autor menciona que las zonas previstas para riego con agua desalada no están a más de 30 kilómetros de la costa, fijando el precio del metro cúbico de agua en superior a los 0,7265 Euros, es decir, 120,9 ptas. en cuanto al coste de explotación. También merece reflexión la elevada contaminación de las plantas desaladoras con la producción de salmuera, destrucción de la flora marítima y elevado consumo energético. El precio del metro cúbico del trasvase del Ebro era de 0,391€ según el estudio de la Secretaria General.

Actualmente en la Comunidad Autónoma de Murcia, han sido puesta en marcha un total de dos plantas ubicadas en los términos municipales de San Pedro del Pinatar (I y II) y Águilas, y en la CC.AA. vecina provincia de Alicante, existen dos más: Alicante (I y II) y Torrevieja. También quedó patente en verano de 2012 que ante la ruptura por una falla del trasvase Tajo-Segura gracias al aumento de producción de las desaladoras se dio servicio a más de tres millones de personas, se trató de una medida de urgencia que fue efectiva, recordemos que el entonces ministro de Medio Ambiente, Miguel Arias Cañete, señaló como fracaso del plan de desaladoras que, tras una inversión de 1.600 millones de euros, en 2011 solo funcionaron al 16\% de su capacidad. En 2012 esa cifra fue mayor, entre otras cosas porque la Comisión Europea ha exigido a España que funcionen tras aportar la mayor parte del dinero para su construcción (diario El País, 2-09-2012)

En cuanto la instalación de redes de abastecimiento del agua desalada, es un aspecto importante, pero poco contemplado en cuanto al impacto medioambiental que supone establecer una red de tuberías y demás instalaciones que proporcionen la elevación y transporte de agua hasta Yecla, también el gasto de energía fósil es muy fuerte para elevar los motores el agua hasta nuestro término.

Otra solución para la aportación de caudales hacia Yecla era la aportación del trasvase Júcar-Vinalopó, teniendo presente que el Júcar también es un río deficitario, se contaba con la aportación de la cuenca del Tajo y Ebro para este suministro, evidentemente tampoco esta propuesta ha sido aceptada, ya que la cuenca del Júcar es muy deficitaria, de hecho históricamente el acuífero de Yecla-Villena-Benejama ha abastecido en parte a la costa mediterránea, localidades turísticas como Benidorm o Alicante han sido las mayores beneficiadas. 


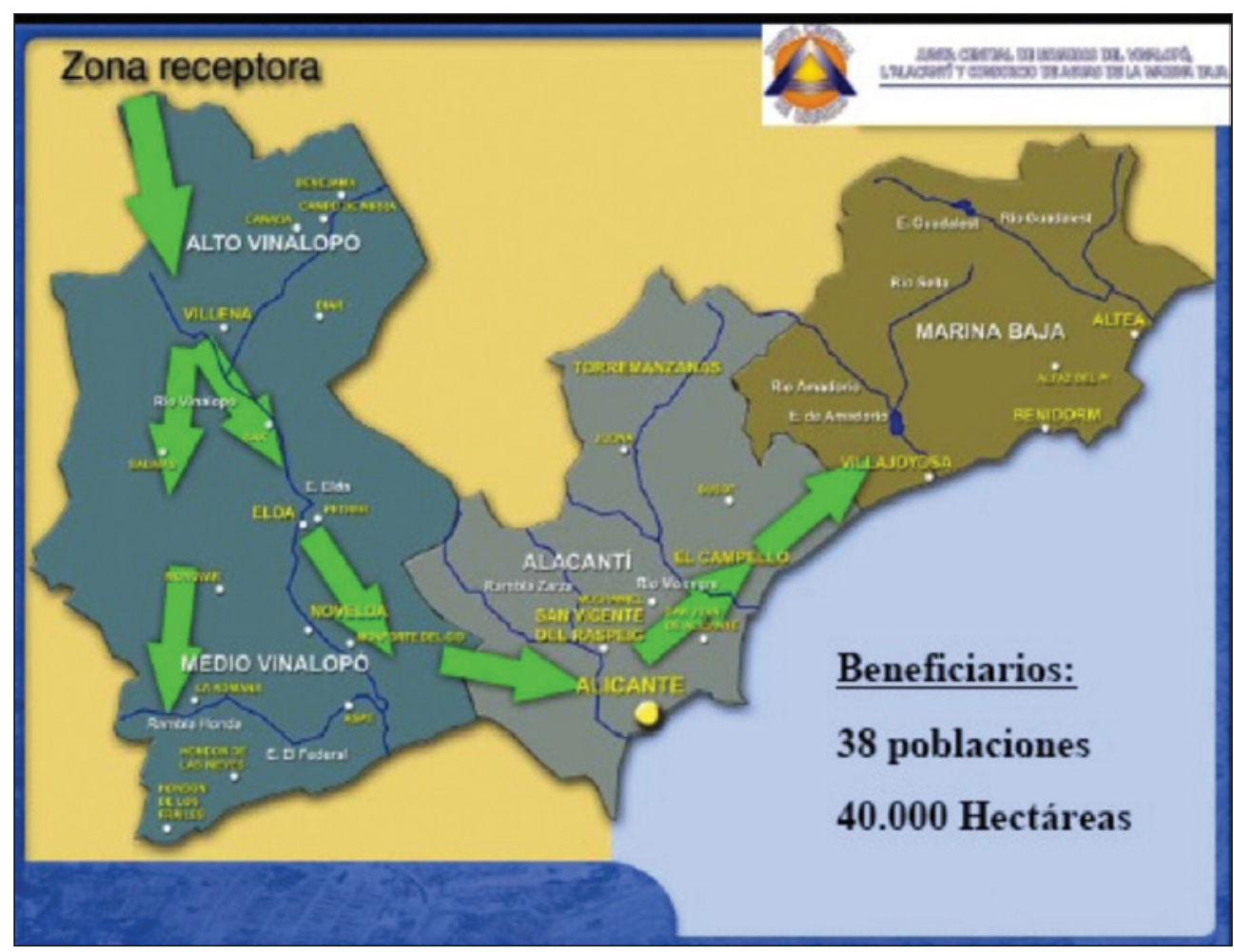

Fuente: Junta Central de usuarios del Vinalopó.

\section{CONSIDERACIONES FINALES}

En el espacio estudiado, el uso del agua ha tenido un marcado carácter desde los primeros pobladores hasta nuestros días, tanto el espacio urbano como el rural se encuentran plagados de elementos que así lo atestiguan, también en el callejero como en las propias viviendas rurales, así como en parcelas y trazados agrarios. El agua fue un bien muy apreciado por nuestros antecesores ante las dificultades que planteaba su captación. Afortunadamente en la actualidad estas dificultades del pasado han sido superadas por la aplicación de Nuevas Tecnologías que promueven captaciones en lugares anteriormente impensables, este hecho junto a una sociedad más abocada al consumo ha repercutido en el abuso de los acuíferos, único medio, por el momento, de abastecimiento en todos los sectores de actividad agraria e industrial, así como poblacional.

La presencia del agua ha marcado la morfología urbana, la ciudad podría haber tenido otra configuración de no ser por la presencia de ramblas y cañadas que han delimitado su crecimiento especialmente en la zona norte, con buen criterio e incluso miedo fundamentado a la escorrentía de las aguas durante muchos siglos, estos pasos naturales fueron respetados por 
los habitantes de la ciudad, a partir del florecimiento industrial generado en la ciudad en los años 60 del pasado siglo, los «límites» del agua han sido eliminados, borrados de tal forma que resultan casi irreconocibles a simple vista; cientos de construcciones y naves industriales se encuentran asentadas en zonas de drenaje, de poco ha servido la memoria histórica de pasadas avenidas así como las ordenanzas municipales del último Plan de Ordenación Urbana que obligan a sobreelevar las construcciones como mínimo a 90 centímetros.

Por otro lado de cara al futuro, la ciudad debe avanzar hacia un crecimiento sostenible que pueda armonizar el desarrollo agrario e industrial con las posibilidades reales de consumo, con ayudas externas como se perfilaban en la aplicación del PHN y que han quedado anuladas. La puesta en marcha del Plan A.G.U.A., el cual propuso la llegada de agua al Altiplano a través de los canales del Taibilla y la desalación todavía no se ha hecho realidad. Estas expectativas alcanzarán mayor viabilidad si existieran proyectos concretos, no una declaración de principios que no se ha visto materializada en actuación alguna, por lo menos hasta la actualidad. También la mentalización de los ciudadanos en el uso racional del agua y la mejora en las técnicas agrarias serán fundamentales en la producción de un espacio bien desarrollado y armónico, en definitiva sostenible de cara a los desafíos de futuro.

Otras cuestiones abordadas pasarían por el imprescindible entendimiento entre todas las fuerzas políticas a la hora de plantear una política hídrica común, un «pacto sobre el agua» que permitiera el uso del liquido elemento como un bien común en el conjunto nacional y no sectorizado por las distintas Comunidades Autónomas ya que muy pocos ríos nacen, se extienden y desembocan en la misma comunidad autónoma y aunque este caso también se produzca, ha de entenderse el agua como un bien común para todos los habitantes del país, independientemente de su lugar de residencia, de hecho también son muchas las personas que nacen en una CC.AA. y por sus propias circunstancias viven en otra, está claro que la producción de riqueza, beneficia a todos si existe por parte del gobierno central una adecuada política que intente corregir desequilibrios y compensar a los territorios más desfavorecidos, por ello abogamos por el entendimiento y el deseo de compartir retos que repercutirán en su conjunto en la estabilidad de los ciudadanos de este país, independientemente de su lugar de residencia.

El tema del agua, desgraciadamente tiene muchas veces un marcado carácter político, lo que ha dificultado o frenado la llegada de soluciones reales y coherentes. La existencia de agua supone creación de riqueza, lo que repercute en la proliferación de negocios, aumento de puestos de trabajo y también probablemente la llegada de la especulación, lo que permite un enriquecimiento inmediato de unos pocos e hipoteca el futuro de muchos o por lo menos perfila un futuro muy incierto para la mayoría de los ciudadanos. Por ello es necesario el sosiego, diálogo, voluntad de entendimiento y mucho trabajo técnico que evalúe situaciones y proponga soluciones eficaces que promuevan el bien común, con el necesario respecto al paisaje, la sostenibilidad y la adecuada ordenación del territorio que abre la puerta a un futuro más esperanzador y sereno.

\section{BIBLIOGRAFÍA}

ÁlVAREZ, L. (2005): Antropología de la Región de Murcia. Colección monografías regionales. Murcia. Consejería de Cultura y Educación de la Región de Murcia. 
BELOQUI, L (2004): «La verdad sobre la desalación del agua del mar». Disponible en: http://www.coiam.org/contenido.php?url_seccion=185\&url_foro=1

CALVO, F. (1999): «Caudales propios y foráneos en una cuenca exagüe: La del Segura». Instituto Universitario de Geografía, Universidad de Alicante, Caja de Ahorros del Mediterráneo, 485-508.

CONESA, C y GARCÍA, E. (2003): «Las áreas históricas de inundación en Cartagena: Problemas de drenaje y actuaciones», Boletín de la Asociación de Geógrafos Españoles, ${ }^{\circ}$ 35, 79-100.

CONESA, C. y ALONSO, F (2006): «El clima de la Región de Murcia. El medio físico de la Región de Murcia», 95-128.

ESPEJO, C (2004): «Campos de golf y medio ambiente. Una interacción necesaria», Cuadernos de Turismo. Universidad de Murcia. $\mathrm{n}^{\circ}$ 14, 67-111.

GIL, A. (2001): «Demanda y disponibilidad de agua». En Geografía de España, Barcelona, Edit. Ariel, 441-454.

GÓMEZ, J.M. (2012): Elevación de aguas para riego en la cuenca del Segura. Cien años del motor Resurrección (1912-2012). Murcia. Fundación Séneca. Agencia de Ciencia y Tecnología.

LÓPEZ, F. (2003): «Primeros estudios analíticos de las aguas potables de Yecla». Yakka, nº $13,151-164$.

LÓPEZ, F. (2004): «Primeros estudios analíticos de las aguas potables de Yecla» (2a parte) Yakka, no 14, 147-166.

MARTÍNEZ, R y OTROS (2000): El medio ambiente. Enciclopedia divulgativa de la Historia natural de Jumilla-Yecla. Vol.1 Ed. CAM (Somehn)

MORALES, A. (1972): El Altiplano de Jumilla-Yecla. Murcia. Departamento de Geografía de la Universidad de Murcia.

MORALES, A. (2000): Visión del PHN (Informe solicitado por la Secretaria de Estado de Aguas y Costas del Ministerio de Medio Ambiente)

MORALES, A. (2001): Agua y territorio en la Región de Murcia. Murcia. Fundación Centro de Estudios Históricos e Investigaciones locales.

MORALES, F.J. (2004): «Efectos del abastecimiento de agua en el paisaje urbano de Yecla (Murcia)», Boletín de la Asociación de Geógrafos Españoles, $\mathrm{n}^{\circ}$ 37. 299-315.

MURCIA Y EL AGUA. Historia de una pasión. (2005): Comisión Mixta Asamblea Regional de Murcia y Real Academia Alfonso X el Sabio de Murcia.

O.N.U. (2003): «Protección de la calidad y el suministro de los recursos de agua dulce: aplicación de criterios integrados para el aprovechamiento, ordenación y uso de los recursos de agua dulce». Edita FAO.

PUCHE, J. (2004): «Fuentes Públicas de Yecla». El Yeclano Ausente. no 69.

PUCHE, A. (1989): «Síntesis geológica del término municipal de Yecla», Yakka, nº 1 , 91-109.

RODRÍGUEZ, T y Otros (1980) «Estudio geológico en el sector Carche-Salinas. Zona Prebética (prov. De Murcia y Alicante)» Bol. IGME, no 88, vol 4, 527-548.

ROMERO, M.A. y Otros (2009): «Avances en estudios sobre desertificación» aportaciones al Congreso Internacional sobre Desertificación en memoria del profesor John B. Thornes. Universidad de Murcia. 
SORIANO, J.M. (2004): «Bases para la implantación de la agenda 21 en Yecla. Yakka. Revista de estudios Yeclanos. Documento anexo al $\mathrm{n}^{\circ} 14$.

VERA, J.F. (2000): Informe sobre el PHN (Informe solicitado por la Secretaria de Estado de Aguas y Costas del Ministerio de Medio Ambiente).

\section{Otras fuentes:}

Actas Capitulares. Excmo. Ayuntamiento de Yecla.

Archivo Histórico Municipal de Yecla. Sección Servicios Municipal de Aguas, Legajos 493494 (distribución de riegos).

\section{Cartografía:}

P.G.O.U. de Yecla 1984.

P.G.O.U. de Yecla 2013 (avance)

SERVICIO GEOGRÁFICO NACIONAL. Hoja 845(27-33) 1:25000.Año 2008

CONSEJERIA DE POLÍTICA TERRITORIAL, OBRAS PÚBLICAS Y URBANISMO.

Fotografía aérea. CARTOMUR. 
